\title{
Experimental and simulation-based analysis of asymmetrical spherical roller bearings as main bearings for wind turbines
}

\author{
Amin Loriemi ${ }^{1} \mathbb{D} \cdot$ Georg Jacobs ${ }^{1} \cdot$ Sebastian Reisch ${ }^{1} \cdot$ Dennis Bosse $^{1} \cdot$ Tim Schröder $^{1}$ \\ Received: 28 November 2020 / Accepted: 4 March 2021 / Published online: 29 March 2021 \\ (c) The Author(s) 2021
}

\begin{abstract}
Symmetrical spherical roller bearings (SSRB) used as main bearings for wind turbines are known for their high load carrying capacity. Nevertheless, even designed after state-of-the-art guidelines premature failures of this bearing type occur. One promising solution to overcome this problem are asymmetrical spherical roller bearings (ASRB). Using ASRB the contact angles of the two bearing rows can be adjusted individually to the load situation occurring during operation. In this study the differences between symmetrical and asymmetrical spherical roller bearings are analyzed using the finite element method (FEM). Therefore, FEM models for a three point suspension system of a wind turbine including both bearings types are developed. These FEM models are validated with measurement data gained at a full-size wind turbine system test bench. Taking into account the design loads of the investigated wind turbine it is shown that the use of an ASRB leads to a more uniform load distribution on the individual bearing rows. Considering fatigue-induced damage an increase of the bearing life by $62 \%$ can be achieved. Regarding interactions with other components of the rotor suspension system it can be stated that the transfer of axial forces into the gearbox is decreased significantly.
\end{abstract}

\section{Experimentelle und simulationsbasierte Analyse asymmetrischer Pendelrollenlagern als Hauptlager von Windenergieanlagen}

\section{Zusammenfassung}

Symmetrische Pendelrollenlager, die als Hauptlager für Windenergieanlagen eingesetzt werden, sind für ihre hohe Tragfähigkeit bekannt. Dennoch kommt es trotz korrekter Auslegung nach aktuellen Richtlinien auch bei diesem Lagertyp zu vorzeitigen Ausfällen. Eine vielversprechende Lösung dieses Problems sind asymmetrische Pendelrollenlager. Bei asymmetrische Pendelrollenlager können die Druckwinkel der beiden Lagerreihen individuell an die im Betrieb auftretende Lastsituation angepasst werden. In dieser Studie werden die Unterschiede zwischen symmetrischen und asymmetrischen Pendelrollenlagern mit Hilfe der Finite-Elemente-Methode (FEM) analysiert. Dazu werden FEM-Modelle der Dreipunktlagerung einer Windenergieanlage für beide Lagertypen entwickelt. Diese FEM-Modelle werden mit Messdaten, die an einem Gondelprüfstand gewonnen werden konnten, validiert. Unter Berücksichtigung der Auslegungslasten der untersuchten Windenergieanlage wird gezeigt, dass der Einsatz eines asymmetrischen Pendelrollenlagers zu einer gleichmäßigeren Lastverteilung der einzelnen Lagerreihen führt. Unter Berücksichtigung von ermüdungsbedingten Schäden kann eine Erhöhung der Lagerlebensdauer um 62\% erreicht werden. Hinsichtlich der Wechselwirkungen mit anderen Komponenten der Rotorlagerung kann festgestellt werden, dass die Übertragung von Axialkräften in das Getriebe deutlich verringert wird.

Amin Loriemi

amin.loriemi@cwd.rwth-aachen.de

Georg Jacobs

georg.jacobs@cwd.rwth-aachen.de

Sebastian Reisch

Sebastian.reisch@cwd.rwth-aachen.de
Dennis Bosse

dennis.bosse@cwd.rwth-aachen.de

Tim Schröder

tim.schroeder@cwd.rwth-aachen.de

1 CWD—Chair for Wind Power Drives, RWTH Aachen University, Campus-Boulevard 61, 52074 Aachen, Germany 


\section{Introduction}

The three-point suspension is one of the most widely used rotor suspension concepts for onshore wind turbines. In this concept, non-torsional rotor loads are supported by a single main bearing as a locating bearing and by the torque supports of the gearbox. Compared to a four-point suspension its simple design is statically well determined and therefore robust against system deformations. However, this also results in additional requirements for the gearbox and the main bearing. The gearbox is conceptually loaded by high transverse forces and under certain circumstances also by axial forces as additional input loads. The main bearing must have an adequate static and dynamic load carrying capacity and at the same time tolerate misalignment due to the elastic deformation of the main shaft and the base frame. For this reason, SSRB are mainly used for this application as the geometrical characteristics of this bearing type prevent the build-up of reaction moments. Nevertheless, despite of a correct design according to current guidelines, financially serious main bearing damages occur $[1$, 2]. As a result, bearing manufacturers have begun to adapt the standard catalogue bearings by various modifications to the specific operating conditions in the field of wind energy. The most up-to-date and conceptually most significant innovation is the ASRB, which is supposed to have a better utilization of the two bearing rows and an increased axial stiffness [3]. Therefore, the main objective of this study is to investigate the influence of the main bearing type on the mechanical bearing load. This is done via a comparison between a classical SSRB and a corresponding ASRB. As comparison criteria, the rolling element loads, the bearing stiffness as well as the resulting constraining forces and movements at the gearbox input are used. To determine the internal forces and to analyze the mechanical effects occurring in the examined rotor suspension system of a $2.75 \mathrm{MW}$ turbine, efficient finite element models are set up and validated with two test setups on a full-size wind turbine system test bench. By the comparison of the two bearing types in

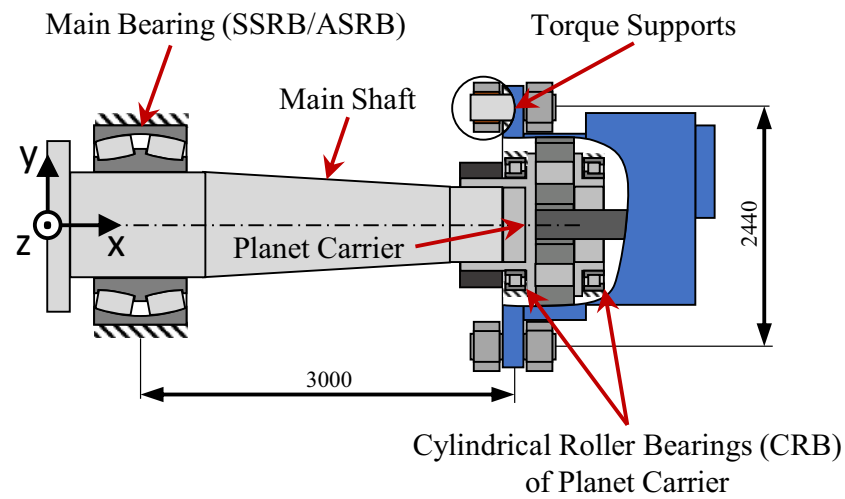

Fig. 1 Three-point suspension of the research nacelle

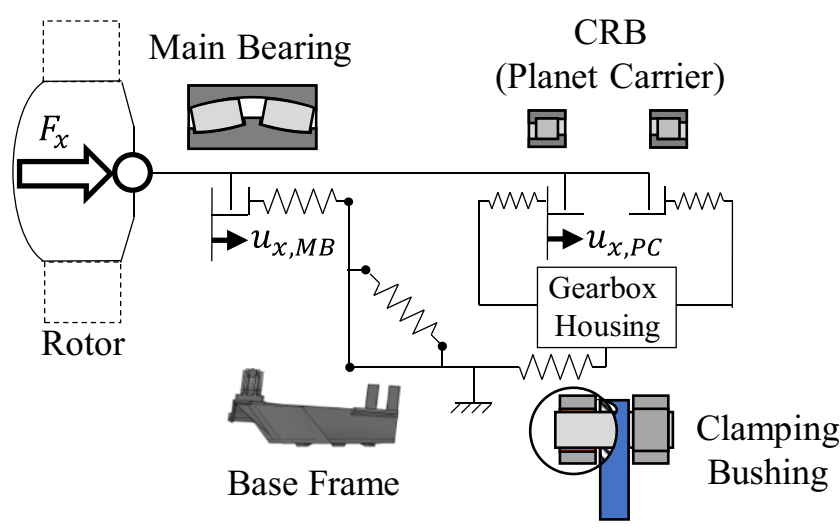

Fig. 2 Principle sketch of the axial force transmission paths [5]

the system environment, the mechanical consequences from integrating an ASRB in a three-point suspension regarding the bearing itself and its interaction with the gearbox are investigated and quantified.

\section{Rotor suspension system}

The analysis of this study refers to a generic $2.75 \mathrm{MW}$ research nacelle that has been built in the context of the project "Loads on Drivetrain Components of Wind Turbine Generators" [4]. The rotor suspension system is designed as a three-point suspension, using a spherical roller bearing as a main bearing (Fig. 1).

In this study, two suspension configurations are investigated that differ only in the spherical roller bearing used. The following table gives the specification of the integrated bearings.

As can be seen in the table, the bearings differ essentially only in the nominal contact angle. The three-stage gearbox has a planetary stage as a first stage followed by two spur gear stages. The planet carrier of the planetary stage is connected to the main shaft by a shrink disc. Next to the main bearing, rotor loads are conceptually supported by the planet carrier of the first gearbox stage. The planet carrier itself is supported by two cylindrical roller bearings (CRB). Loads acting on the planet carrier are thereby transmitted via these bearings into the gearbox housing. At last these loads are transmitted over the clamping bushings of the torque supports into the base frame.

Focusing on axial loads which are applied at the rotor, the main bearing is supposed to bear these loads as a locating bearing. Nevertheless, if the axial stiffness of the main bearing is not high enough, it is possible that the axial clearance of the planet carrier bearings is overcome and axial forces are also transmitted into the gearbox. Fig. 2 sketches these relationships. 
If the planet carrier bearings support axial loads, the rotor suspension system is axially overdetermined. To analyze the resulting distribution of internal loads the elastic properties of all the components of the force transmission paths have to be considered. A simplified approach for evaluating the force transmission, ignoring individual stiffnesses and nonlinear effects, as clearances, is not suited for this purpose. In this paper, the axial displacement of the main bearing $u_{x, M B}$ is defined as the relative displacement of the main bearing inner ring relative to the outer ring. Additionally, the displacement of the planet carrier $u_{x, P C}$ is defined as the relative displacement of the planet carrier against the gearbox housing.

\section{Methods}

The mechanical analysis of the two main bearing designs is done with detailed FEM models of the considered research nacelle. State-of-the-art modelling techniques are used to model the individual components in the force transmission path. Both main bearing designs have also been tested on a full scale test bench [4]. Based on measurement data the FEM models are validated and fundamental relationships are derived from experiment and simulation. Finally, the FEM model is used to calculate expected load states occurring during field operation. Therefore load time series are derived from aeroelastic multibody simulation (MBS) and classified. The expected lifetime is then calculated by evaluating the resulting rolling element load distribution of the two main bearings for these design loads.
Table 1 Specification of spherical roller bearings (rot: bearing row on the rotor side; gbx: row on the gearbox side)

\begin{tabular}{lll}
\hline Bearing type & SSRB & ASRB \\
\hline Inner diameter [mm] & 710 & 710 \\
Outer diameter [mm] & 1030 & 1030 \\
Width [mm] & 315 & 315 \\
Nominal Contact angle (rot/gbx) $\left[^{\circ}\right]$ & $10.3 / 10.3$ & $6.7 / 15.4$ \\
Number of rolling elements (rot/gbx) & $30 / 30$ & $30 / 29$ \\
Mass [kg] & 895 & 877 \\
Dynamic load capacity [kN] & 10,400 & 9200 \\
\hline
\end{tabular}

\subsection{FEM simulation}

In previous studies a modelling technique for spherical roller bearings has been developed and validated [6]. Thereby for reducing the computational costs, the rolling elements has been replaced by nonlinear spring elements which are coupled to the raceway surfaces of the inner and outer ring. The stiffness characteristics of the spring elements has been derived from contact simulations of the roller-raceway contact. Individual FEM models had to be derived for the two bearing setups, as the varying contact angle must be taken into account structurally in the arrangement of the spring elements (Fig. 3).

Loads are applied at a reference point which is coupled to the rotor flange of the main shaft. According to the test setup used for experimental validation, adjacent components such as adapters are represented in the model.

In former studies [6] the gearbox has only been considered in a strongly simplified manor. Planet carrier and gearbox housing have been replaced by rigid beam elements transmitting forces and moments into the clamping bushings without considering structural elasticity. Also the cylindrical roller bearings of the planet carrier have only been considered as an axial acting stop connector element,
Fig. 3 Arrangement of spring elements for SSRB and ASRB

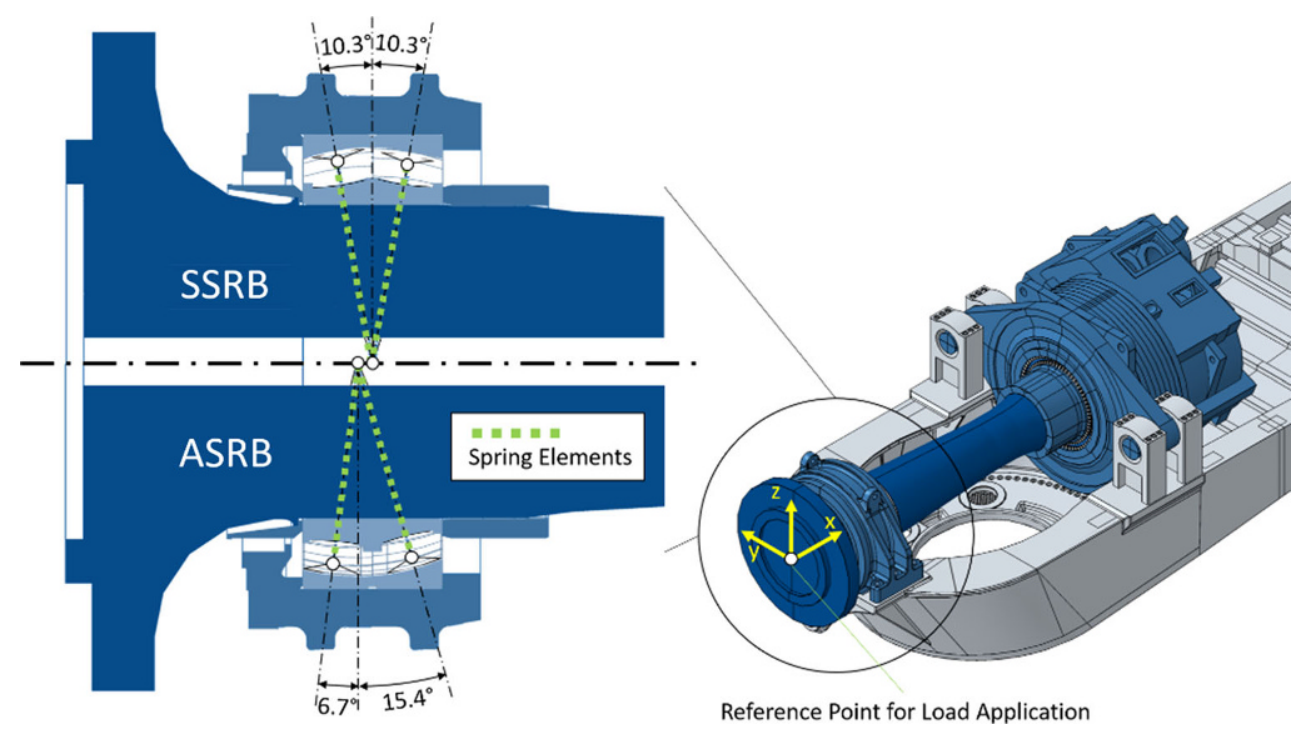


Table 2 Test plan for test bench measurements

\begin{tabular}{lllll}
\hline Load & Range & Incrementation & Static Map & Number of Load Cases \\
\hline Fx & -200 to $500 \mathrm{kN}$ & $50 \mathrm{kN}$ & Fx-Mx & 120 \\
$\mathrm{Mx}$ & 0 to $1750 \mathrm{kNm}$ & $250 \mathrm{kNm}$ & Fx-My & 225 \\
$\mathrm{My}$ & -1500 to $2000 \mathrm{kNm}$ & $250 \mathrm{kNm}$ & Fx-Mz & 165 \\
$\mathrm{Mz}$ & -1250 to $1250 \mathrm{kNm}$ & $250 \mathrm{kNm}$ & Mx-My & 120 \\
& & & Mx-Mz & 88 \\
& & - & My-Mz & 165 \\
- & - & - & - & $\sum 883$ \\
\hline
\end{tabular}

so the axial clearance of the planet carrier bearing arrangement could be considered. Radial stiffnesses and resulting tilting stiffness of the planet carrier bearing arrangement were neglected thereby. This simplifications are avoided in this study by enhancing the model by a more detailed modelling of the gearbox as applied by Reisch [5]. Within this model all structural components as the planet carrier and the gearbox housing are considered. Additionally, the CRBs of the planet carrier are also modelled. In the modelling of the CRBs the roller element contacts have also been replaced with nonlinear spring elements. With that the elastic properties of the bearing arrangement is considered as far as possible without including a cost intensive contact simulation. Based on the developed FEM model, the rotor suspension system can be analyzed considering all elastic properties of the component within the force transmission paths.

\subsection{Experimental validation}

To validate the developed FEM system model and also to analyze the different main bearing types by experiment, two test bench setups have been realized. In each setup a different spherical roller bearing according to Table 1 has been mounted. All other mechanical components and the measurement system have been kept the same. For measuring the local relative displacement of the drivetrain at the

Table 3 Design loads for analyzing operating behavior

\begin{tabular}{l} 
Operation \\
$3 \mathrm{~m} / \mathrm{s} \leq v_{\text {hub }} \leq 25 \mathrm{~m} / \mathrm{s}$ (incremetation $\left.=1 \mathrm{~m} / \mathrm{s}\right)$ \\
- each with yaw misalignment of $-8^{\circ}, 0^{\circ}, 8^{\circ}$ \\
- time share according to Weibull distribution \\
Start up and normal shut down \\
$1000 \mathrm{x} /$ year at $v_{\text {hub }}=5 \mathrm{~m} / \mathrm{s}$ \\
$50 \mathrm{x} /$ year at $v_{\text {hub }}=12.5 \mathrm{~m} / \mathrm{s}$ \\
$50 \mathrm{x} /$ year at $v_{\text {hub }}=25.0 \mathrm{~m} / \mathrm{s}$ \\
Idling \\
At $v_{\text {hub }}=3 \mathrm{~m} / \mathrm{s}$ (according to Weibull distribution) \\
1 week $/$ year at $v_{\text {hub }}=12.5 \mathrm{~m} / \mathrm{s}$ \\
1 week $/$ year at $v_{\text {hub }}=25.0 \mathrm{~m} / \mathrm{s}$ \\
At $v_{\text {hub }}=30 \mathrm{~m} / \mathrm{s}$ (according to Weibull distribution) \\
\hline
\end{tabular}

main bearing, planet carrier and the torque supports, inductive distance sensors and LVDT (linear variable differential transformer) transducers have been used as it has already been done in previous studies [6]. As the main objective of the conducted experiments is the validation of the developed FEM models, the selected test plans include static load points. In each test plan two input loads are varied in a typical operating range. A detailed specification is given in Table 2.

The effects of applied thrust, torsion and bending moments are investigated. Transverse forces are neglected, since their effect on the drivetrain is equivalent and weaker compared to corresponding bending moments. Moreover, their variation during field operation is significantly smaller than the varied load components. In total six static maps are recorded including 883 load combinations which are applied statically at the test bench in addition to the rotor weight.

\subsection{Bearing life calculation}

Since the different bearing types are investigated with regard to their application as main bearings of wind turbines, the resulting operational load situation has to be considered. For that reason a state-of-the-art aeroelastic MBS model [7] of the complete wind turbine (hub height: $60 \mathrm{~m}$; rotor diameter: $80 \mathrm{~m}$ ) is used for rotor load calculation in accordance to IEC 61400-1 [8]. Within the MBS model the drivetrain is reduced to a torsional three-mass oscillator. Loads acting on the rotor blades are calculated in respect to local wind speed and wind direction given by turbulent wind fields generated with TurbSim [9]. This is done using blade element theory in its implementation in the AeroDyn code [10]. Design load cases considered are shown in Table 3.

For the defined load cases the Weibull parameters correspond to wind class II of IEC 61400-1 [8]. The simulation results of the MBS model are given as load time series at the rotor flange. For deriving a limited number of equivalent static load cases, which can be analyzed with the developed static FEM model of the rotor suspension system, a six-dimensional classification of the time series data has been carried out. With that the complex load collective is 
Fig. 4 Comparison of measured and simulated displacement at main bearing and planet carrier [5]

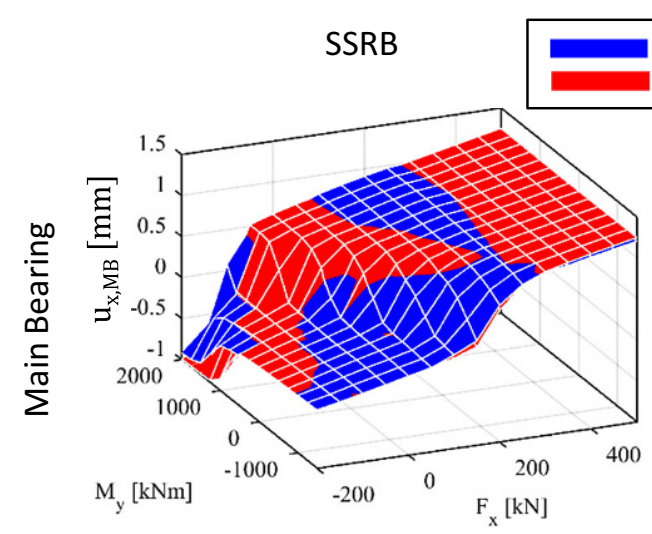

Measurement Simulation
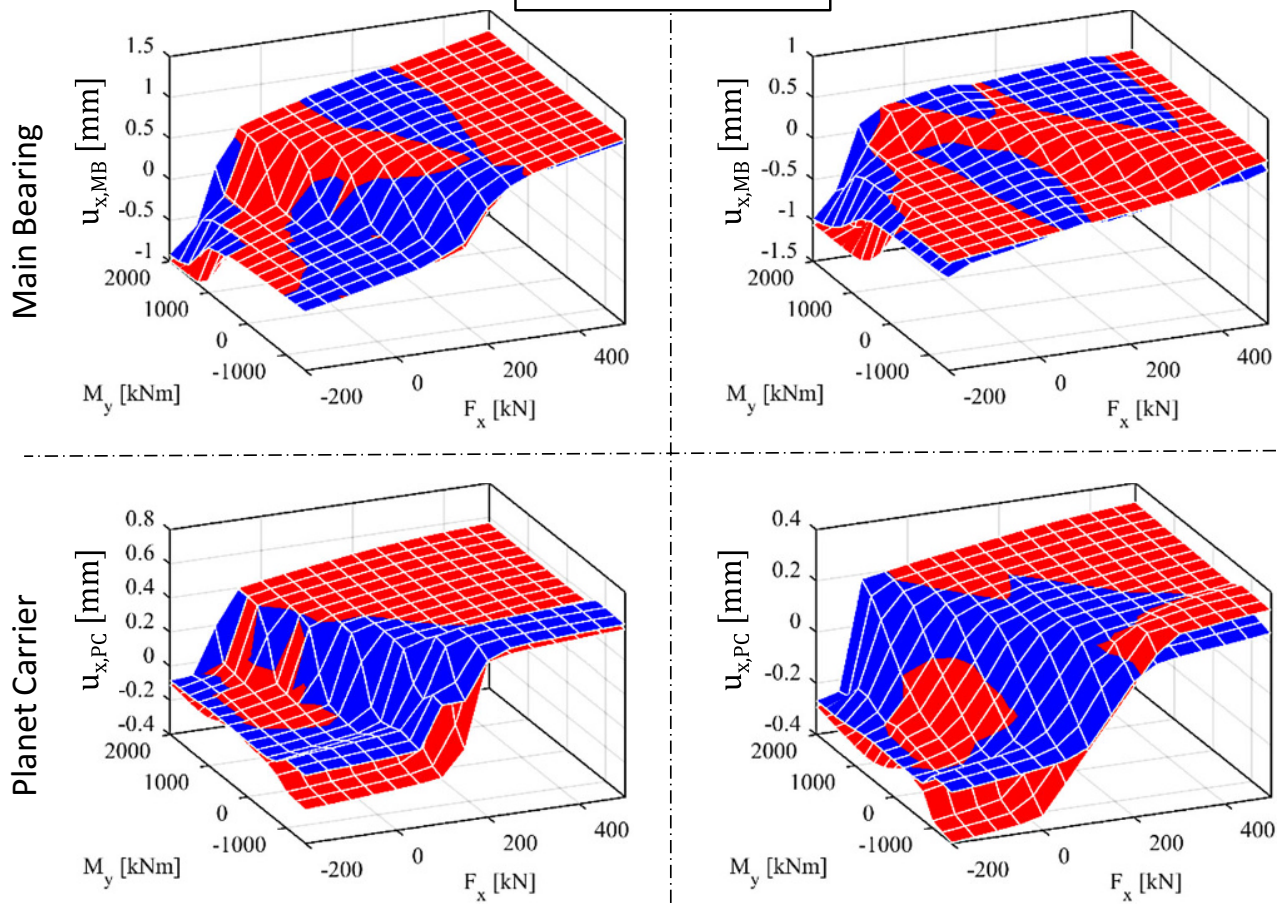

reduced to only 3343 representative static load cases and corresponding time percentages.

Bearing life calculation is performed for the different main bearing types on basis of the derived equivalent load cases. This is done in accordance to Harris [11] on the basis of the rolling element load distributions of the individual bearing rows. The nominal lifetime of a bearing row is composed of the inner and outer ring's lifetime according to following equations:

$$
\begin{aligned}
& L_{10, \mathrm{rot} / \mathrm{gbx}}=\left(L_{10, I R}^{-9 / 8}+L_{10, O R}^{-9 / 8}\right)^{-8 / 9} \\
& L_{10, I R / O R}=\left(\frac{Q_{c, I R / O R}}{Q_{e, I R / O R}}\right)^{-10 / 3}
\end{aligned}
$$

$Q_{c} \quad$ Dynamic load capacity of the single contact according to [10]

$Q_{e} \quad$ Equivalent rolling element load

rot Rotor side

$I R \quad$ Inner ring

$O R$ Outer ring

gbx Gearbox side
The equivalent rolling element load is thereby calculated as

$$
\begin{aligned}
& Q_{e, I R}=\left(\frac{1}{Z} \sum_{j=1}^{Z} Q_{j}^{4}\right)^{1 / 4} \\
& Q_{e, O R}=\left(\frac{1}{Z} \sum_{j=1}^{Z} Q_{j}^{4.5}\right)^{1 / 4.5}
\end{aligned}
$$

where $Z$ is the number of rolling elements per row and $Q_{\mathrm{j}}$ is the contact force of the individual rolling element, which is derived using the validated FEM model. For $k$ representative load cases and corresponding time percentages $q_{k}$ the total lifetime of the bearing is calculated as:

$$
\begin{aligned}
& L_{10, \mathrm{rot} / \mathrm{gbx}}=\frac{\sum q_{k}}{\sum \frac{q_{k}}{L_{10, k}}} \\
& L_{10}=\left(L_{10, \mathrm{rot}}^{-9 / 8}+L_{10, \mathrm{gbx}}^{-9 / 8}\right)^{-8 / 9}
\end{aligned}
$$

\section{Results}

\subsection{Experimental validation}

For validation of the developed FEM model, static load maps have been measured at the $4 \mathrm{MW}$-system test bench. 
Fig. 5 Load states of SSRB and ASRB depending on thrust and bending moment

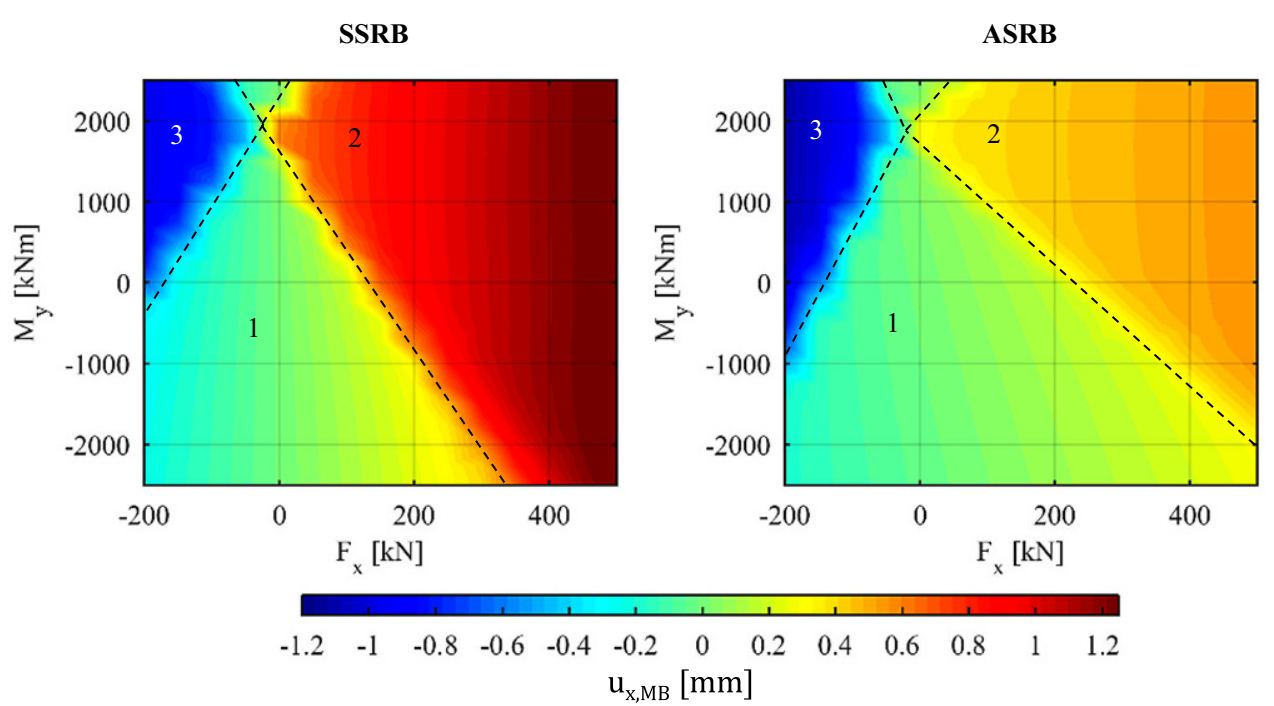

Principle sketch of bearing load state

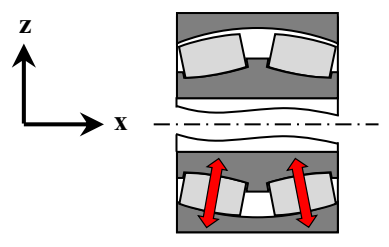

1

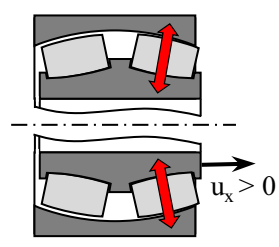

2

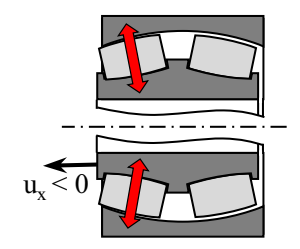

3
By comparing measured and simulated displacements, some model parameters were adjusted to minimize the deviation. As fitting parameters, the bearing clearance of the individual bearing locations and the relative mounting position of the individual drive train components were used. These parameters are subject to a certain scatter due to the manufacturing and assembly process and have to be estimated in advance. Therefore, a subsequent adjustment of these parameters based on the measurements is necessary. In this context, the spherical clearance of the SSRB was corrected from 250 to $210 \mu \mathrm{m}$ and for the ASRB it has been corrected from 350 to $180 \mu \mathrm{m}$. The axial clearance of the CRB arrangement of the planet carrier has been adjusted from 450 to $670 \mu \mathrm{m}$. In the following, the static map FXMy will be analyzed as an example, as all relevant effects can be seen most clearly here. In Fig. 4 the measured and simulated axial, relative displacement at the main bearing and the planet carrier is shown for the SSRB and ASRB.

It can be stated that the results of the simulation correspond very well with the measurements. For the most part, the same displacements are calculated for the individual combinations of thrust and bending moment as they occur when the same load combinations are applied on the test bench. Also the nonlinear curve properties, which are mainly due to the clearance of the main bearing, is shown by the simulation.
Comparing the two main bearing types, the SSRB has larger displacement range than the ASRB shown by simulation and experiment. In addition to the thrust, the axial displacement of both bearings also depends on the bending moment applied to the rotor flange and the resulting inner loading on the main bearing (Fig. 5).

Evaluating simulated rolling element load distributions of the individual bearing rows the static map can be divided into three regions. In region 1 the main bearing is primarily subjected to radial loads and therefore strikes radially. In this region main bearing loads are distributed to both bearing rows. In region $2 \& 3$ the main bearing is subjected to high axial loads which overcome the axial bearing clearance. This completely takes the load off one bearing row and only the other bearing row bears all main bearing loads. Looking at the axial displacements in region 2, it can also be seen that in the range of positive displacements the ASRB has a much higher axial stiffness. Additionally, comparing the ASRB with the SSRB it is stated that for a wider load spectrum, main bearing loads are distributed to both bearing rows (region 1 ).

\subsection{Bearing life}

The validated FEM models are used to calculate the rolling element load distributions of the considered main bearings 
Fig. 6 Histograms of rolling element load distribution of SSRB and ASRB for load collective [5]
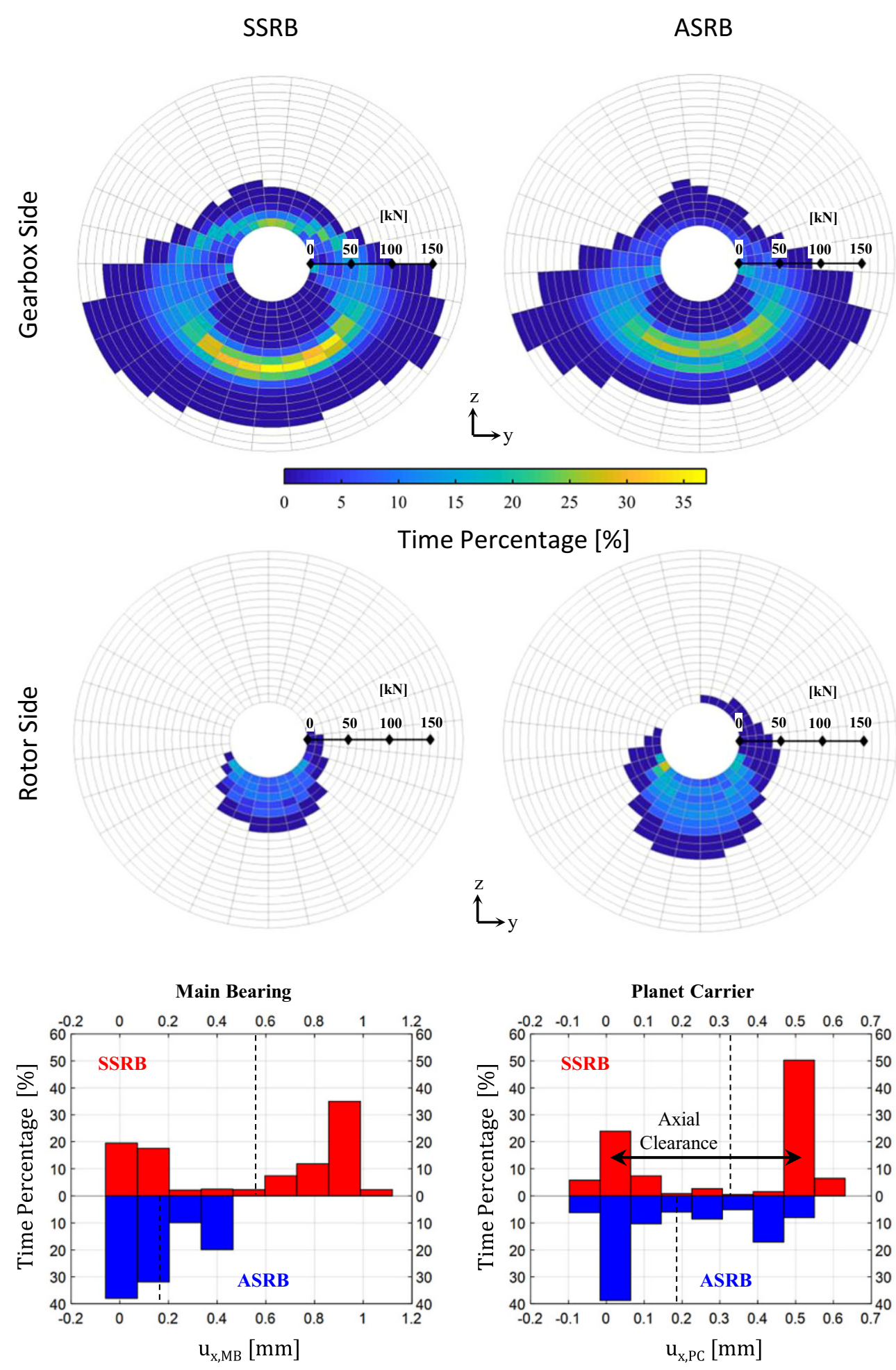

Planet Carrier

Fig. 7 Histograms of axial displacement at main bearing and planet carrier during operation for the load collective derived from MBS simulations. Histograms of the individual rolling element loads can be calculated taking into account the time percentages associated with the individual load cases. These histograms are shown for the individual bearing rows and bearing types in Fig. 6 .
It can be seen that in both bearing types, the gearbox side bearing row is subjected to higher loads, which is due to the unidirectional effect of thrust acting during operation. Comparing both bearing types, it can be stated that during operation the ASRB distributes the bearing loads more evenly between the two bearing rows. This results in a re- 
Fig. 8 Histograms of axial forces at cylindrical roller bearings of planet carrier
CRB (Rotor Side)

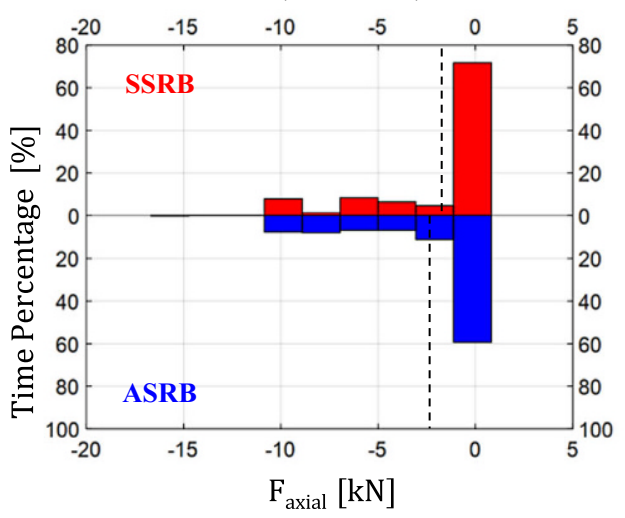

CRB (Generator Side)

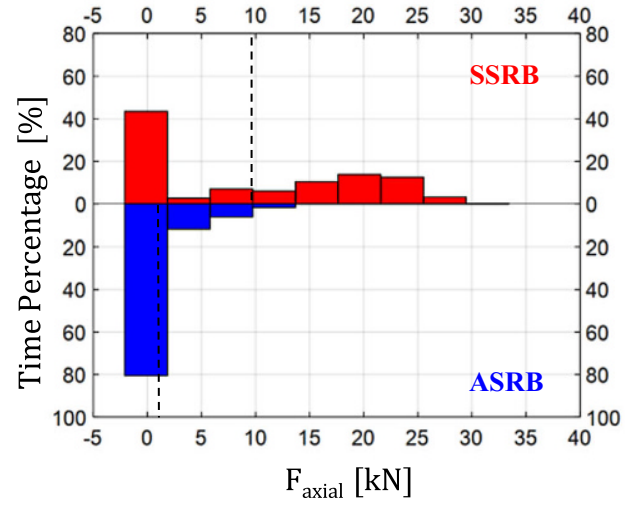

duction of the load on the bearing row on the gearbox side, whereas the rotor side is subjected to higher loads compared to the SSRB. The calculation of the resulting nominal lifetime $L_{10}$ on the basis of the bearing load distribution in operation shows a clear difference between the main bearing types. For the SSRB a lifetime of $421,500 \mathrm{~h}$ can be expected, whereas a $62 \%(681,100 \mathrm{~h})$ longer life results for the ASRB.

\subsection{Interaction with gearbox}

In addition to the main bearing loads the transmission of axial forces into the gearbox is analyzed. Therefore in Fig. 7, histograms are given for the axial displacement at the main bearing and the planet carrier.

For the SSRB axial displacement at the main bearing up to $1.1 \mathrm{~mm}$ occurs during operation, whereas for the ASRB axial displacement is limited to $0.4 \mathrm{~mm}$. Regarding axial displacement of the planet carrier it can be stated that in a configuration with the SSRB, the planet carrier strikes axially against the bearing ribs most of the operating time. In contrast to that, using an ASRB, the planet carrier is mostly located within the clearance of the bearing arrangement. This is also represented in the histograms of resulting axial forces of the planet carrier bearing shown in Fig. 8 .

For the CRB on the rotor side a similar loading occurs for both main bearing types. Differences arise mainly for the $\mathrm{CRB}$ on the generator side, which in the case of a SSRB as main bearing is exposed to considerably higher axial forces during operation. Here axial forces are almost three times higher than with the ASRB.

\section{Discussion}

The use of an ASRB as a main bearing shows significant advantages regarding the internal load distribution and the interaction with other drivetrain components. It is shown that through increasing the contact angle on the gearbox side, the bearing loads occurring during operation are more evenly distributed on the two bearing rows. This results in a reduction of the loads on the gearbox side bearing row for the ASBR and an extension of the expected nominal bearing lifetime by $62 \%$. However, this lifetime calculation only considers contact forces and resulting fatigue-induced damage. Other damage and wear mechanisms like micropitting, spalling, smearing or fretting [2] are not considered in this analysis. The consideration of these highly nonlinear mechanisms requires a detailed calculation of the tribological and dynamic processes within the contact. However, this is not possible with the calculation methods presented here, since on the one hand the contact is modeled in a simplified way as a spring stiffness and on the other hand a quasi-static consideration of the loading is assumed. Nevertheless, since main bearing design and rolling element selection is made based on fatigue life and static load ratings only [2], the presented results can be used to make a meaningful comparison between SSRB and ASRB. Hereby it can be stated that the ASRB is better adapted to the operating loads of wind turbines due to the adjusted contact angles, which take into account the asymmetrical loading caused by thrust. With that the risk of fatigue-induced damage and a resulting premature failure is reduced. Since contact forces and the resulting contact pressures are reduced, a positive influence can also be assumed for other damage and wear mechanisms, which are dependent on these variables.

The ASRB also has advantages in the use within the rotor suspension system. As it has a higher axial stiffness, axial displacement at the planet carrier during operation is more limited than with the SSRB. As a result, the axial bearing clearance of the planet carrier bearing is overcome only to a lesser extent and the resulting axial forces of the $\mathrm{CRB}$ at the generator side are also significantly lower. This increases the safety to a fatigue-related crack of the bearing rib. It is important to note that the rotor suspension system under consideration has torque supports with elastomeric clamping bushings of compared to the main bearing low axial stiffness. Axial displacements which overcome the 
axial clearance of the planet carrier bearings therefore cause only small constraining forces. Other drivetrain concepts which include a stiffer connection of the gearbox to the base frame would expect correspondingly higher constraining forces and would benefit even more from the higher axial stiffness of the ASRB.

\section{Conclusion}

With the use of the developed FEM models and experimental investigations on the system test bench, differences between SSRB and ASRB have been analyzed at component and system level. It is shown that the ASRB is better adapted to the operational load situation of a wind turbine. The adapted contact angles cause the loads to be distributed more evenly between the two bearing rows, whereas the SSRB is mainly loaded on the bearing row at the gearbox side. Due to the reduced internal load level, the calculated lifetime of the ASRB increases by $62 \%$ compared to the SSRB. Within the three-point suspension, the use of an ASRB as a main bearing has the additional advantage of a higher axial stiffness, which improves its functionality as a locating bearing and reduces axial loads transmitted into the gearbox significantly.

In this study, a suitable ASRB already available on the market was used for the investigations carried out. An optimization of the contact angles to the given load collective has therefore not been carried out. It can be assumed that through an optimization of the contact angles an even further reduction of the contact forces can be achieved. This would customize the bearing to the given wind turbine (in particular the rotor design) and the given site conditions.

Acknowledgements The authors would like to thank the Federal Ministry for Economic Affairs and Energy for the support and their project partners, who provided the equipment, insight and expertise which contributed greatly to this successful joint research. They also want to thank the industrial partners and the German Research Association for Power Transmission Engineering (FVA) for the good teamwork while building the research nacelle.

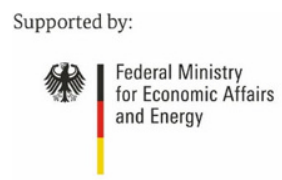

on the basis of a decision by the German Bundestag

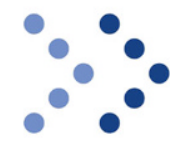

sharing drive innovation
Funding Open Access funding enabled and organized by Projekt DEAL.

Open Access This article is licensed under a Creative Commons Attribution 4.0 International License, which permits use, sharing, adaptation, distribution and reproduction in any medium or format, as long as you give appropriate credit to the original author(s) and the source, provide a link to the Creative Commons licence, and indicate if changes were made. The images or other third party material in this article are included in the article's Creative Commons licence, unless indicated otherwise in a credit line to the material. If material is not included in the article's Creative Commons licence and your intended use is not permitted by statutory regulation or exceeds the permitted use, you will need to obtain permission directly from the copyright holder. To view a copy of this licence, visit http://creativecommons.org/licenses/by/4. $0 \%$

\section{References}

1. Hart E (2019) Wind turbine main-bearing loading and wind field characteristics. Wind Energy 22(11):1534-1547

2. Hart E (2020) A review of wind turbine main bearings: design, operation, modelling, damage mechanisms and fault detection. Wind Energy Sci 5(1): 105-124

3. Schaeffler https://www.schaeffler.com/remotemedien/media/_shared_ media/08_media_library/01_publications/schaeffler_2/brochure/ downloads_1/osp_de_en.pdf. Accessed 11 Dec 2020

4. Reisch S (2017) Challenges and opportunities of full size nacelle testing of wind turbine generators. In: The Proceedings of the JSME international conference on motion and power transmissions 2017, The Japan Society of Mechanical Engineers Kyoto

5. Reisch S (2020) Einfluss der Lagerbauform auf die mechanische Beanspruchung des Hauptlagers in Windenergieanlagen. RWTH Aachen, Aachen

6. Reisch S (2018) Experimental and model-based analysis of the force transmission in a rotor bearing support system. J Physics Conf Ser 1037(6). https://doi.org/10.1088/1742-6596/1037/6/062028

7. Matzke D (2018) Validation of the gearbox load calculation of a wind turbine MBS model. J Physics Conf Ser 1037(6). https:// doi.org/10.1088/1742-6596/1037/6/062025

8. IEC 61400-1, 2005: Wind turbines-Part 1: Design requirements

9. NREL https://www.nrel.gov/wind/nwtc/turbsim.html. Accessed 13 Nov 2020

10. NREL https://www.nrel.gov/wind/nwtc/aerodyn.html. Accessed 13 Nov 2020

11. Harris TA, Kotzalas MN (2007) Essential Concepts of Bearing Technology, 5th edn. CRC Press, Boca Raton 